\title{
Selection of upland rice lines in advanced yield trials and response to abiotic stress
}

\author{
ARIF TIRTANA ${ }^{1, \vartheta}$, BAMBANG SAPTA PURWOKO ${ }^{2, v \vee}$, ISWARI SARASWATI DEWI ${ }^{3}$, \\ TRIKOESOEMANINGTYAS ${ }^{2}$ \\ ${ }^{1}$ Program of Plant Breeding and Biotechnology, Department of Agronomy and Horticulture, Faculty of Agriculture, Institut Pertanian Bogor. Jl. Meranti, \\ IPB Dramaga Campus, Bogor 16680, West Java, Indonesia. Tel./fax. +62-251-8629353, "email: tirtarif22@gmail.com \\ ${ }^{2}$ Department of Agronomy and Horticulture, Faculty of Agriculture, Institut Pertanian Bogor. Jl. Meranti, IPB Dramaga Campus, Bogor 16680, West \\ Java, Indonesia. Tel./fax.+62-251-8629353, "vemail: bspurwoko@apps.ipb.ac.id \\ ${ }^{3}$ Indonesian Center for Agricultural Biotechnology and Genetic Resources Research and Development. Jl. Tentara Pelajar No. 3A, Bogor 16111, West
} Java, Indonesia

Manuscript received: 20 September 2021. Revision accepted: 30 September 2021.

\begin{abstract}
Tirtana A, Purwoko BP, Dewi IS, Trikoesoemaningtyas. 2021. Selection of upland rice lines in advanced yield trials and response to abiotic stress. Biodiversitas 22: 4694-4703. Breeding programs to obtain superior upland rice varieties with high productivity and adaptive in dryland must be prioritized to maximize the potential of dryland. This research aimed to obtain information on the agronomic performance of upland rice lines in advanced yield trials and select the best lines with high productivity and tolerance to drought stress and aluminum toxicity. Advanced yield trials were conducted from November 2016 until March 2017 in Bogor and Sukabumi using a randomized complete block design, where three replications were nested in the environments. Aluminum and drought stress evaluations were conducted at Muara Research Station, Bogor, in May-June 2018 and September-October 2018. Based on the selection index, twelve lines were selected with superior agronomic characters and high yield potential. These lines had characteristics as follows: days to harvesting (110.2-116.0 days), number of filled grains (70.6-101.3 grains), number of unfilled grains (27.9-58.4 grains), and productivity (2.2-2.9 tons $\mathrm{ha}^{-1}$ ). Evaluation of drought tolerance showed four lines with better drought tolerance than the drought-sensitive check IR20. The aluminum tolerance evaluation obtained two tolerant lines and nine lines with moderate responses to aluminum toxicity. The selected lines need to be further evaluated in multilocation trials.
\end{abstract}

Keywords: Aluminum, drought, multivariate analysis, productivity, weighted index

\section{INTRODUCTION}

Rice is one of Indonesia's most important staple foods. The need and demand for rice will continue to increase along with the increase in population. Indonesia's population projection from 2015 to 2035 by Pitoyo et al. (2018) shows that the population will increase every year. In 2035, Indonesia's population is predicted to reach 304.9 million people. One of the main problems that hinder the increase in national rice production is agricultural land conversion. The Ministry of Agriculture (2019) reported that the lowland rice field area in 2018 was 7.1 million hectares and experienced shrinkage of $12.97 \%$ (1.06 million hectares) compared to 2017.

The utilization of dryland for upland rice cultivation is one strategy that can increase national rice production. The Ministry of Agriculture (2019) stated that dryland has a potential land area of 11.7 million hectares. However, dryland has poor soil fertility levels compared to lowland. The average productivity of upland rice in 2014-2017 was 3.3 tons of dry unhusked grain $(\mathrm{GKG}) \mathrm{ha}^{-1}$, while the productivity of lowland rice reached 5.4 tons $\mathrm{GKG} \mathrm{ha}^{-1}$ (Ministry of Agriculture 2019). Low productivity of upland rice is caused by poor crop management practices, a lack of high-yielding cultivars, also abiotic and biotic stresses (Saito et al. 2018). Some of the main abiotic stresses in dryland are drought stress and aluminum toxicity.
Therefore, the development of upland rice varieties for high yields and tolerance to drought stress and aluminum toxicity needs to be prioritized to maximize dryland utilization.

Applying biotechnology to conventional breeding methods can increase the effectiveness and accelerate upland rice breeding programs. In conventional rice breeding, it takes at least six generations to obtain pure lines (Dwivedi et al. 2015). Anther culture techniques can accelerate the acquisition of pure lines by forming doubled haploid plants in the first generation to shorten the breeding process (Dwivedi et al. 2015; Mishra and Rao 2016). Anther culture techniques can also be combined with other biotechnological techniques, such as mutation induction techniques. The availability of vast genetic variability is a prerequisite for plant genetic improvement. Mutation induction techniques can be used to establish and increase genetic variability in breeding materials to make selection effective (Viana et al. 2019).

Advanced yield trial is one of the stages in a plant breeding program. Advanced yield trials should be done in several locations or seasons to evaluate yield potential and assess genotype-environment interactions' effect before selecting breeding materials (Gomez and Gomez 1984). The selection process requires an effective and efficient selection method to determine the superior lines. One method that can be used is a selection index (Anshori et al. 
2021). The selection index is an indirect selection method that uses several characters correlated with the main character and combines all information into an index as the basis in the selection process (Falconer and Mackay 1996). Determination of the secondary selection character and the weighting of each character in constructing the selection index model can be done by multivariate analysis, such as path analysis (Oladosu et al. 2018; Saha et al. 2019; Sudeepthi et al. 2020) and principal component analysis (Alsabah et al. 2019; Akbar et al. 2021; Anshori et al. 2021).

In the previous yield trials conducted by Tijarah (2016) and Sari and Purwoko (2018), ten doubled haploid rice lines with superior agronomic characters were obtained. In addition, there were ten mutant rice lines derived from gamma-ray irradiation, which had good agronomic characteristics and high yield potential. These doubled haploid and mutant lines will be tested further in advanced yield trials. Selection will be conducted in the advanced yield trial to select superior lines. Then, evaluation for drought and aluminum tolerance at the seedling stage was performed to obtain information about tolerant lines. The purpose of this research was to obtain information on the agronomic performance of upland rice lines in the advanced yield trials and select high-yielding and tolerant lines to drought and aluminum stress for multilocation trials.

\section{MATERIALS AND METHODS}

\section{Advanced yield trials}

The experiments were conducted from November 2016 until March 2017 at the Sawah Baru Experimental Station, Dramaga, Bogor and Bojong Village, Cikembar, Sukabumi. Twenty lines consisted of ten mutant lines derived from gamma-ray irradiation (E-2-CK1-BP, E-4CK1-BP, E-8-CK1-BP, E-16-CK1-BP, E-33-CK1-BP, E34-CK1-BP, E-37-CK1-BP, E-38-CK1-BP, E-43-CK1-BP, E-48-CK1-BP) and ten doubled haploid lines derived from anther culture (CG-9-5-1-2, CG-9-53-1-3, CG-12-30-1-3, HR-4-12-1-1, HR-2-6-1-1, HR-1-12-2-2, HR-5-7-1-1, HR5-9-1-1, HR-6-5-1-3, HR-8-5-2-1) were evaluated. Two check varieties, namely IR64 and Inpago 10, were used.

The experiments used a randomized complete block design (RCBD) with a single factor, and three replications were nested in the environments. The treatments consisted of 20 upland rice lines and two check varieties so that there were 66 experimental units at each location. The size of each experimental unit was $3 \mathrm{~m} \times 3 \mathrm{~m}$ with the plant spacing of $30 \mathrm{~cm} \times 15 \mathrm{~cm}$. The seeds were planted by direct seeding as many as 5-7 seeds per hole. The fertilizer doses used were $120 \mathrm{~kg} \mathrm{ha}^{-1}$ Urea, $100 \mathrm{~kg} \mathrm{ha}^{-1} \mathrm{SP}-36,100$ $\mathrm{kg} \mathrm{ha}^{-1} \mathrm{KCl}$, and $240 \mathrm{~kg} \mathrm{ha}^{-1}$ Phonska (15-15-15). The SP36 and $\mathrm{KCl}$ fertilizers were applied two weeks after planting (WAP). Meanwhile, Urea fertilizer was applied two times at 2 and 5 WAP with doses of $40 \mathrm{~kg} \mathrm{ha}^{-1}$ and 80 $\mathrm{kg} \mathrm{ha}^{-1}$. The Phonska (15-15-15) fertilizer was applied at 8 WAP.
The agronomic characters observed were plant height measured at the generative stage $(\mathrm{cm})$, the number of productive tillers, days to flowering was observed when $50 \%$ of plants in each plot showed flowering, days to harvesting was observed when $90 \%$ of the panicles in each plot have turned yellow, panicle length $(\mathrm{cm})$, panicle density (grain per panicle), number of filled grains per panicle, number of unfilled grains per panicle, number of total grains per panicle, percentage of filled grains (\%), percentage of unfilled grains (\%), the weight of 1000 grains $(\mathrm{g})$, and productivity were obtained by converting grain weight per plot to grain yield per hectare (ton ha-1).

Before performing combined variance analysis, the test of homogeneity of error variances for each character was examined by F-test using the procedure described by Gomez and Gomez (1984). The test revealed homogeneity of error variances at the two locations for all observed characters. The observed data were examined by combined variance analysis to assess the effect of genotype $(\mathrm{G})$, location (E), and $\mathrm{G} \times \mathrm{E}$ interactions (Gomez and Gomez 1984). Estimations of genotypic coefficient of variation (GCV) and phenotypic coefficient of variation (PCV) were calculated using the equations mentioned by Abebe et al. (2017). The GCV and PCV values were classified into three categories, i.e., low $(<10 \%)$, moderate $(10-20 \%)$, and high $(>20 \%$ ) (Sudeepthi et al. 2020). Estimation of broadsense heritability $\left(\mathrm{h}^{2}{ }_{\mathrm{bs}}\right)$ was calculated by the equation proposed by Falconer and Mackay (1996). The $\mathrm{h}^{2}{ }_{\text {bs }}$ value was categorized into three categories, i.e., low $\left(\mathrm{h}^{2}{ }_{\mathrm{bs}}<0.2\right)$, moderate $\left(0.2 \leq \mathrm{h}^{2}{ }_{\mathrm{bs}} \leq 0.5\right)$, and high $\left(\mathrm{h}_{\mathrm{bs}}^{2}>0.5\right)$ (Akbar et al. 2021).

Determination of the selection character was based on the character that was correlated with productivity and had a large direct effect on productivity. Correlation and path analyses were calculated following the procedure described by Singh and Chaudhary (1979). Data for principal component analysis and selection index were standardized using Z-scores following the formula proposed by Jolliffe and Cadima (2016). Principal component analysis was used to obtain the loading value of each selection character on the selected principal component as the weighting in the selection index. The selection index was based on the formula proposed by Falconer and Mackay (1996): I = $b_{1} X_{1}+b_{2} X_{2}+b_{3} X_{3}+\ldots+b_{n} X_{n}$ where I was the selection index, $b_{n}$ was the weight of the $n^{\text {th }}$ character, $X_{n}$ was the standardized phenotypic value with Z-score for the $n^{\text {th }}$ character.

\section{Drought tolerance screening}

The experiment was conducted from SeptemberOctober 2018 in a greenhouse at the Muara Experimental Station, Indonesia Center of Rice Research, Pasir Jaya, Bogor. A total of twelve selected lines based on the selection index in Table 9 consisted of E4-CK1-BP, E8CK1-BP, E33-CK1-BP, E37-CK1-BP, E38-CK1-BP, E43CK1-BP, E48-CK1-BP, HR1-12-2-2, HR5-7-1-1, HR5-91-1, HR8-5-2-1, and CG9-53-1-3 were evaluated. In addition, two check varieties, namely IR20 as a droughtsensitive check and Salumpikit as a drought-tolerant check, were used. 
Table 1. Evaluation of tolerance level against drought stress based on leaf rolling

\begin{tabular}{cll}
\hline Score & \multicolumn{1}{c}{ Category } & \multicolumn{1}{c}{ Description } \\
\hline 0 & Highly tolerant & Leaves healthy \\
1 & Tolerant & Leaves start to fold (shallow) \\
3 & Mild tolerant & Leaves folding (deep V-shape) \\
5 & Moderate & Leaves fully cupped (U-shape) \\
7 & Mild sensitive & Leaves margins touching (0-shape) \\
9 & Sensitive & Leaves tightly rolled \\
\hline
\end{tabular}

Table 2. Evaluation of tolerance level against drought stress based on leaf drying

\begin{tabular}{|c|c|c|}
\hline Score & Category & Description \\
\hline 0 & Highly tolerant & No symptoms \\
\hline 1 & Tolerant & Slight tip drying \\
\hline 3 & Mild tolerant & $\begin{array}{l}\text { Tip drying extended up to } 1 / 4 \text { length } \\
\text { in most leaves }\end{array}$ \\
\hline 5 & Moderate & $1 / 4$ to $1 / 2$ of all leaves dried \\
\hline 7 & Mild sensitive & $\begin{array}{l}\text { More than } 2 / 3 \text { of all leaves fully } \\
\text { dried }\end{array}$ \\
\hline 9 & Sensitive & All plants apparently dead \\
\hline
\end{tabular}

Table 3. Evaluation of plant recovery ability after drought stress

\begin{tabular}{cll}
\hline Score & \multicolumn{1}{c}{ Category } & \multicolumn{1}{c}{ Description } \\
\hline 1 & Tolerant & 90-100\% plants recovered \\
3 & Mild tolerant & 70-89\% plants recovered \\
5 & Moderate & 40-69\% plants recovered \\
7 & Mild sensitive & 20-39\% plants recovered \\
9 & Sensitive & 0-19\% plants recovered \\
\hline
\end{tabular}

A randomized complete block design (RCBD) was used with a single factor and three replications. The experiment was conducted at the seedling stage. A total of 10 seeds from each genotype were planted in a concrete tank with dimensions $5.3 \mathrm{~m}$ long, $1.3 \mathrm{~m}$ wide, $0.8 \mathrm{~m}$ deep. Plant spacing of $20 \mathrm{~cm} \times 10 \mathrm{~cm}$ was used. Watering was only done until the plants were 14 days after planting (DAP). After that stage, the plants were not watered and let to grow.

Scoring was conducted on three drought tolerance traits: leaf rolling, leaf drying, and plant recovery ability. The scoring was based on the Standard Evaluation System (SES) of rice by IRRI (2013), listed in Table 1-3. The drought tolerance scoring based on leaf rolling and leaf drying symptoms were conducted when the droughtsensitive check variety (IR20) died or had reached a score of 9. After scoring for drought tolerance, all tested genotypes were re-watered and maintained for ten days, and then plant recovery ability was scored.

The observed data were analyzed by calculating the mode of each genotype. Simultaneous evaluation of all drought tolerance traits was conducted using a selection index. The determination of the selection index was based on the formula proposed by Falconer and Mackay (1996).

\section{Aluminum tolerance screening}

The experiment was conducted from May-June 2018 in a greenhouse at the Muara Experimental Station, Indonesia Center of Rice Research, Pasir Jaya, Bogor. The genetic materials evaluated were the same as the lines in the drought stress screening experiment, viz., twelve selected lines based on the selection index in Table 9. In addition, two check varieties, namely Limboto as an aluminumtolerant check and ITA131 as an aluminum-sensitive check, were used. Other materials used were $0.2 \% \mathrm{HgCl}_{2}$ solution, $1 \mathrm{~N} \mathrm{HCl}, 1 \mathrm{~N} \mathrm{NaOH}$, Yoshida nutrient solution, and $\mathrm{AlCl}_{3} \cdot 5 \mathrm{H}_{2} \mathrm{O}$ as a source of aluminum.

The experiment was designed as a randomized complete block design (RCBD) with a single factor and two replications. The experiment was conducted at the seedling stage. Before sowing, the seeds were first soaked in $0.2 \%$ $\mathrm{HgCl}_{2}$ solution for one minute, rinsed with distilled water, and soaked again with distilled water for 24 hours. A total of 10 seedlings from each genotype were sown on rice husk charcoal media for 7 days. Next, the seedlings were transferred to plastic containers with dimensions $40 \mathrm{~cm} \times$ $25 \mathrm{~cm} \times 15 \mathrm{~cm}$, filled with \pm 4 liters of Yoshida nutrient solution with 0 and $40 \mathrm{ppm} \mathrm{Al} \mathrm{concentrations.} \mathrm{The} \mathrm{Yoshida}$ test solution was maintained at $\mathrm{pH} 4.0 \pm 0.2$ with $1 \mathrm{~N} \mathrm{HCl}$ or $1 \mathrm{~N} \mathrm{NaOH}$. The Yoshida test solution was aerated by pumping air into the plastic containers. The Yoshida test solution was replaced every week.

After 20 days of treatment, the root length of each genotype at treatment levels 0 and $40 \mathrm{ppm} \mathrm{Al}$ was measured. The tolerance level of each genotype to aluminum toxicity was based on the relative root length (RRL). The RRL was calculated by comparing root length at $40 \mathrm{ppm} \mathrm{Al}$ with root length at $0 \mathrm{ppm} \mathrm{Al}$. The RRL values were categorized into five categories, i.e., highly tolerant (RRL>0.8), tolerant $(0.6<\mathrm{RRL} \leq 0.8)$, moderate $(0.4<\mathrm{RRL} \leq 0.6)$, sensitive $(0.2<\mathrm{RRL} \leq 0.4)$, and highly sensitive $(0.2 \leq \mathrm{RRL})$ (Hermanasari et al. 2021).

\section{RESULTS AND DISCUSSION}

\section{Agronomic character performance, variance component, and heritability}

The combined analysis of variance showed that genotype $(\mathrm{G})$ had a highly significant effect on all observed traits (Table 4). The result showed that there was a presence of high variability among the genotypes. Environment (E) significantly affected most traits except panicle length, panicle density, number of total grains per panicle, and productivity (Table 4). The significant effects of the environment indicate that the observed performance of agronomic characters is different at the two locations. Interaction of genotype and environment $(\mathrm{G} \times \mathrm{E})$ also significantly affected most traits except panicle length, panicle density, and the number of total grains per panicle. These significant differences of $\mathrm{G} \times \mathrm{E}$ interactions imply different responses of the genotypes at different locations. Genetic variability is a prerequisite for selecting genotypes. Agronomic characters with significant genotype, location, and interaction factors indicate a large amount of genetic variability among the genotypes (Oladosu et al. 2018). 
Table 4. Combined analysis of variance for agronomic traits at two locations

\begin{tabular}{|c|c|c|c|c|}
\hline \multirow{2}{*}{ Traits } & \multicolumn{3}{|c|}{ F Values } & \multirow{2}{*}{ CV (\%) } \\
\hline & Genotype (G) & Environment (E) & $\mathbf{G} \times \mathbf{E}$ & \\
\hline Plant height & $66.99^{* * *}$ & $4.19^{*}$ & $2.23^{* *}$ & 4.71 \\
\hline Number of productive tillers & $3.32^{* *}$ & $20.86^{* *}$ & $1.83^{*}$ & 13.83 \\
\hline Days to flowering & $12.59^{* *}$ & $5.00^{*}$ & $7.39^{* *}$ & 2.82 \\
\hline Days to harvesting & $7.66^{* *}$ & $61.58^{* *}$ & $4.47^{* *}$ & 1.99 \\
\hline Panicle length & $16.62^{* * *}$ & $3.21^{\mathrm{ns}}$ & $0.89^{\text {ns }}$ & 4.86 \\
\hline Panicle density & $10.15^{\text {** }}$ & $2.01^{\mathrm{ns}}$ & $1.60^{\mathrm{ns}}$ & 9.21 \\
\hline Number of filled grains & $7.82^{* *}$ & $122.23^{* *}$ & $2.38^{* *}$ & 16.26 \\
\hline Number of unfilled grains ${ }^{\#}$ & $10.44^{* *}$ & $92.48^{* *}$ & $2.77^{* *}$ & 12.09 \\
\hline Number of total grains & $10.84^{* *}$ & $3.42^{\text {ns }}$ & $1.27^{\mathrm{ns}}$ & 11.98 \\
\hline Percentage of filled grains & $9.61^{* *}$ & $180.00^{* *}$ & $3.87^{* *}$ & 11.56 \\
\hline Percentage of unfilled grains ${ }^{\#}$ & $8.51^{* *}$ & $161.14^{* *}$ & $2.92^{* *}$ & 9.89 \\
\hline Weight of 1000 grains & $15.42^{* *}$ & $147.90^{* *}$ & $1.99^{*}$ & 6.12 \\
\hline Productivity ${ }^{\#}$ & $3.54^{* *}$ & $3.91^{\mathrm{ns}}$ & $3.29^{* *}$ & 15.52 \\
\hline
\end{tabular}

Note: CV: coefficient of variation; **: highly significant at $1 \%$ level of significance; *: significant at $5 \%$ level of significance; ns: nonsignificant at $5 \%$ level of significance; \#: transformed data with square root transformation $(\mathrm{x})^{0.5}$

The coefficient of variation (CV) for all observed characters ranged from 1.99-16.26\% (Table 4). The lowest $\mathrm{CV}$ was found in days to harvesting, while the number of filled grains showed the highest $\mathrm{CV}$. The square root transformation was applied to the number of unfilled grains, percentage of unfilled grains, and productivity because these characters' CVs were $>20 \%$ before data transformation. Before the analysis, any $\mathrm{CV}$ value that exceeds the reasonable limit should be transformed. A high CV value indicates low trial reliability (Gomez and Gomez 1984).

Estimation of variance component, genotypic coefficient of variation (GCV), and phenotypic coefficient of variation (PCV) of each character are shown in Table 5. The GCV ranged from 1.45-25.82\%. Meanwhile, the PCV ranged from $2.25-31.80 \%$. The PCV value in this study was relatively higher than the GCV value for all observed characters. The influence of environmental factors may cause this result. Similar results were reported by Saha et al. (2019) and Sudeepthi et al. (2020).

There was only one character with a high GCV (>20\%), which was the number of filled grains $(25.82 \%)$. The characters with moderate GCV (10-20\%) were plant height, panicle length, panicle density, number of unfilled grains, number of total grains, and weight of 1000 grains (Table 5). The character with a relatively high GCV value indicates an opportunity of improving the character through selection (Abebe et al. 2017). On the contrary, the estimates of GCV were low $(<10 \%)$ for the number of productive tillers, days to flowering, days to harvesting, percentage of filled grains, percentage of unfilled grains, and productivity (Table 5). The low GCV value indicates inadequate variability and a slight possibility for character improvement (Sudeepthi et al. 2020). Therefore, selection would be effective if using characters with high GCV. According to Akbar et al. (2021), the GCV value should be combined with the heritability value to be a good criterion for determining the selection character.
Broad-sense heritability $\left(\mathrm{h}^{2} \mathrm{bs}\right)$ is the ratio of the genotypic variance to the phenotypic variance (Falconer and Mackay 1996). Estimation of broad-sense heritability is shown in Table 5. The estimate of heritability in this study ranged from 0.12-0.97. All observed characters showed high heritability $(>0.50)$ except for the number of productive tillers, days to flowering, days to harvesting, and productivity. The characters with moderate heritability $(0.20-0.50)$ were the number of productive tillers $(0.45)$, days to flowering (0.42), and days to harvesting (0.42). Meanwhile, productivity $(0.12)$ has a low heritability $(<0.20)$. The high heritability indicates that the observed characters are more influenced by genetic factors than environmental factors in their expression (Saha et al. 2019). The high heritability could increase the effectiveness of selection (Akbar et al. 2021). On the other hand, the low heritability may be caused by the considerable influence of environmental factors on a character's expression (Abebe et al. 2017). In the present study, productivity has the lowest heritability value. This result was in line with the productivity's GCV value, which was relatively low (Table 5 ), indicating that direct selection based on productivity is ineffective (Akbar et al. 2021). Simultaneous selection with several characters correlated with productivity can be used as an alternative for improving grain yields.

\section{Correlation between agronomic characters}

Correlation analysis is used to measure the degree and direction of relationships between various agronomic characters. The results of the correlation analysis in Table 6 show that the correlation coefficients varied among the agronomic characters. The number of filled grains (0.54) and percentage of filled grains (0.58) had a significant and positive correlation coefficient with productivity. Similar results were reported by Oladosu et al. (2018) and Sudeepthi et al. (2020). The positive correlation indicates that the characters' response is in line with the productivity. Therefore, selection for increasing the number and percentage of filled grains will increase productivity. 
Table 5. Estimation of variance component, coefficient of variation, and broad-sense heritability for agronomic traits

\begin{tabular}{|c|c|c|c|c|c|}
\hline Traits & $\sigma^{2} g$ & $\sigma^{2} p$ & GCV $(\%)$ & $\operatorname{PCV}(\%)$ & $\mathbf{h}^{2}{ }_{b s}$ \\
\hline Plant height & 244.54 & 252.91 & 15.47 & 15.73 & 0.97 \\
\hline Number of productive tillers & 1.19 & 2.65 & 6.89 & 10.28 & 0.45 \\
\hline Days to flowering & 5.00 & 11.84 & 2.66 & 4.10 & 0.42 \\
\hline Days to harvesting & 2.75 & 6.60 & 1.45 & 2.25 & 0.42 \\
\hline Panicle length & 377.89 & 428.17 & 15.13 & 16.10 & 0.88 \\
\hline Panicle density & 146.91 & 210.66 & 15.55 & 18.62 & 0.70 \\
\hline Number of filled grains & 170.54 & 258.65 & 25.82 & 31.80 & 0.66 \\
\hline Number of unfilled grains & 47.94 & 80.29 & 11.35 & 14.69 & 0.60 \\
\hline Number of total grains & 49.74 & 87.68 & 18.09 & 24.02 & 0.57 \\
\hline Percentage of filled grains & 6.40 & 7.34 & 9.27 & 9.92 & 0.87 \\
\hline Percentage of unfilled grains & 3.47 & 3.69 & 7.85 & 8.09 & 0.94 \\
\hline Weight of 1000 grains & 0.35 & 0.41 & 10.97 & 11.95 & 0.84 \\
\hline Productivity & 0.02 & 0.17 & 6.79 & 19.34 & 0.12 \\
\hline
\end{tabular}

Note: $\sigma^{2}$ g: genotypic variance; $\sigma^{2} \mathrm{p}$ : phenotypic variance; GCV: genotypic coefficient of variation; PCV: phenotypic coefficient of variation; $h^{2}$ bs: broad-sense heritability

In contrast, days to flowering (-0.63), days to harvesting $(-0.72)$, number of unfilled grains $(-0.46)$, and percentage of unfilled grains (-0.62) had a significant and negative correlation coefficient with productivity (Table 6). These findings were in line with the results reported by Akbar et al. (2019) and Alsabah et al. (2019). The negative correlation indicates that these characters have the opposite response to productivity. As a result, selection for reducing days to flowering and days to harvesting, as well as decreasing the number and percentage of unfilled grains, will improve productivity. The agronomic characters with a significant correlation to productivity need to be evaluated further to develop selection criteria.

\section{Effect of agronomic characters on productivity}

Path analysis is used to determine the direct and indirect effect of the character that correlates with productivity. The results of path analysis are listed in Table 7 . Based on this table, the number of filled grains (1.04) has the highest positive direct effect on productivity. This result is consistent with the correlation analysis, which revealed that the number of filled grains positively correlates with productivity. Similar results were also reported by Akbar et al. (2019) and Oladosu et al. (2018). Days to flowering ($0.05)$, days to harvesting $(-0.42)$, and the number of unfilled grains (-1.50) showed a negative direct effect and also negatively correlated with productivity (Table 7). Similar findings were reported by Alsabah et al. (2019) on days to flowering, Akbar et al. (2019) on days to harvesting, and Saha et al. (2019) on the number of unfilled grains. The character of days to flowering has a small direct effect which means that selection with this character is ineffective. Therefore, the character of days to flowering is not used as a selection character in this study.

The percentage of unfilled grains negatively correlates with productivity but showed a positive direct effect of 0.42 (Table 7). The inconsistent result was also found in the percentage of filled grains, positively correlated with productivity but had a negative direct effect of-1.03 (Table 7). A similar finding regarding the inconsistent results was reported by Saha et al. (2019) on the number of filled grains and the weight of one hundred grains. In this condition, the correlation may be caused by the indirect effect of other characters and makes direct effect ineffective to use (Singh and Chaudhary 1979).

Path analysis showed a coefficient of determination $\left(\mathrm{R}^{2}\right)$ of $72 \%$ (Table 7), indicating that the path analysis model is reasonably representative and has good reliability. The residual effect that cannot be explained by the path analysis model in this study was 53\%. This result indicates that the characters evaluated in path analysis contributed $47 \%$ of variability to the productivity. Meanwhile, the remaining $53 \%$ of variability comes from the influence of environmental factors and other characters that are not included in this analysis. According to the results, days of harvesting, number of filled grains, and number of unfilled grains had a relatively high direct effect and were consistent with the results of correlation analysis. Therefore, these characters are used as selection criteria for improving productivity.

\section{Principal component of agronomic characters}

The principal component analysis reduces complex dataset dimensions, increasing dataset interpretation while minimizing information loss (Jolliffe and Cadima 2016). The principal component analysis revealed that there were four principal components (PC) with eigenvalue $>1$ (Table $8)$. These PCs contributed to $81 \%$ of total variability, with PC1 accounted for 30\%, followed by PC2, PC3, and PC4, respectively, $25 \%, 17 \%$, and $9 \%$. The eigenvalue is used to determine the number of optimal principal components. The principal component with eigenvalue $>1$ indicates relatively high variability. Hence, it can be considered a representative model for the analysis. In contrast, the principal component with eigenvalue $<1$ can be ignored (Kumar et al. 2011). 
Table 6. Phenotypic correlation coefficient between agronomic characters

\begin{tabular}{|c|c|c|c|c|c|c|c|c|c|c|c|c|}
\hline Traits & PH & NPT & DF & DH & PL & PD & NTG & NFG & NUG & PFG & PGH & W1000 \\
\hline NPT & $-0.64^{* * *}$ & & & & & & & & & & & \\
\hline DF & $0.14^{\mathrm{ns}}$ & $0.16^{\mathrm{ns}}$ & & & & & & & & & & \\
\hline DH & $0.21^{\text {ns }}$ & $-0.08^{\mathrm{ns}}$ & $0.88^{* * *}$ & & & & & & & & & \\
\hline PL & $0.89^{* *}$ & $-0.64^{* *}$ & $0.05^{\mathrm{ns}}$ & $0.21^{\mathrm{ns}}$ & & & & & & & & \\
\hline PD & $0.23^{\mathrm{ns}}$ & $-0.45^{*}$ & $-0.19^{\mathrm{ns}}$ & $-0.17^{\mathrm{ns}}$ & $0.21^{\mathrm{ns}}$ & & & & & & & \\
\hline NTG & $0.63^{* *}$ & $-0.66^{* *}$ & $-0.13^{\mathrm{ns}}$ & $-0.04^{\mathrm{ns}}$ & $0.69^{* *}$ & $0.85^{* *}$ & & & & & & \\
\hline NFG & $0.34^{\mathrm{ns}}$ & $-0.31^{\mathrm{ns}}$ & $-0.30^{\mathrm{ns}}$ & $-0.31^{\mathrm{ns}}$ & $0.29^{\text {ns }}$ & $0.66^{* *}$ & $0.65^{* *}$ & & & & & \\
\hline NUG & $0.51^{*}$ & $-0.56^{* *}$ & $0.17^{\mathrm{ns}}$ & $0.29^{\mathrm{ns}}$ & $0.61^{* * *}$ & $0.49^{*}$ & $0.68^{* *}$ & $-0.10^{\mathrm{ns}}$ & & & & \\
\hline PFG & $-0.26^{\mathrm{ns}}$ & $0.34^{\mathrm{ns}}$ & $-0.22^{\mathrm{ns}}$ & $-0.32^{\mathrm{ns}}$ & $-0.36^{\mathrm{ns}}$ & $-0.14^{\mathrm{ns}}$ & $-0.29^{\mathrm{ns}}$ & $0.54^{*}$ & $-0.88^{* *}$ & & & \\
\hline PUG & $0.25^{\mathrm{ns}}$ & $-0.32^{\mathrm{ns}}$ & $0.29^{\mathrm{ns}}$ & $0.39^{\mathrm{ns}}$ & $0.33^{\text {ns }}$ & $0.12^{\mathrm{ns}}$ & $0.25^{\mathrm{ns}}$ & $-0.55^{* *}$ & $0.87^{* *}$ & $-0.98^{* *}$ & & \\
\hline W1000 & $0.18^{\mathrm{ns}}$ & $-0.21^{\mathrm{ns}}$ & $0.12^{\mathrm{ns}}$ & $0.12^{\text {ns }}$ & $0.15^{\text {ns }}$ & $-0.33^{\mathrm{ns}}$ & $-0.16^{\mathrm{ns}}$ & $-0.55^{* *}$ & $0.25^{\mathrm{ns}}$ & $-0.50^{*}$ & $0.44^{*}$ & \\
\hline PRD & $0.02^{\text {ns }}$ & $0.04^{\mathrm{ns}}$ & $-0.63^{* *}$ & $-0.72^{* *}$ & $-0.07^{\mathrm{ns}}$ & $0.13^{\text {ns }}$ & $0.06^{\mathrm{ns}}$ & $0.54^{*}$ & $-0.46^{*}$ & $0.58^{* *}$ & $-0.62^{* *}$ & $-0.17^{\mathrm{ns}}$ \\
\hline
\end{tabular}

Note: **: highly significant at $1 \%$ level of significance; *: significant at 5\% level of significance; ns: nonsignificant at 5\% level of significance; PH: plant height; NPT: number of productive tillers; DF: days to flowering; DH: days to harvesting; PL: panicle length; PD: panicle density; NTG: number of total grains; NFG: number of filled grains; NUG: number of unfilled grains; PFG: percentage of filled grains; PUG: percentage of unfilled grains; W1000: weight of 1000 grains; PRD: productivity

Selection in this study aims to obtain high-yielding lines. Therefore, the productivity eigenvector's value must be prioritized, and the other selection characters need to support productivity as the main character. The results of the principal component analysis are shown in Table 8. Based on this table, PC1 was the best principal component that could be used to construct the selection index because productivity has the highest eigenvector $(0.33)$ on PC1. The PC1 also has the highest eigenvalue and proportion of variance of 3.93 and 30\%, respectively. The principal component, which has a high eigenvalue and shows a high eigenvector for the main character, is the best model to construct the selection index (Alsabah et al. 2019; Anshori et al. 2021).

The other selection characters consisted of days to harvesting (-0.14), number of filled grains (0.31), and number of unfilled grains $(-0.46)$ had eigenvector values and directions that were in line with the correlation coefficients and the direct effects of each character on productivity (Table 7). All eigenvectors' positive and negative signs are arbitrary, and only their relative magnitudes and sign patterns are meaningful (Jolliffe and Cadima 2016). In other words, when using eigenvectors as the weight index, the sign patterns of eigenvectors must be matched with the sign patterns of correlation and path coefficients.

Since productivity is the most crucial character and has the highest economic value compared to other selection characters, productivity should have the highest weighting. Akbar et al. (2019), Akbar et al. (2021), and Alsabah et al. (2019) assigned the weighting of productivity character three times greater than the weighting of other characters. This weighting intends to maximize the selection towards high-yielding lines. Based on these considerations, this study's weighting for productivity character was made three times greater than the original eigenvector value on PC1. Meanwhile, the weighting for days of harvesting, number of filled grains, and number of unfilled grains used the actual eigenvector values on PC1 (Table 8). The model of weighted selection index (I) in this study was formulated as follows: $\mathrm{I}=(3 \times 0.33 \times \mathrm{PRD})+(0.31 \times \mathrm{NFG})-(0.46 \times \mathrm{NUG})-$ $(0.14 \times \mathrm{DH})$ where $\mathrm{PRD}$ was productivity, NFG was number of filled grains, NUG was number of unfilled grains, and DH was days to harvesting. The index values for all genotypes were calculated using the obtained formula. Next, the index values were sorted from the highest to the lowest index value. The selected genotypes had a positive index value and higher than the check varieties' index value.

\section{Selection index}

The selection results using the weighted selection index model are listed in Table 9. The E-43-CK1-BP line had the highest index value of 1.89 , while the E-34-CK1-BP line had the lowest index value of-3.81. The index values of the IR64 and Inpago 10 check varieties were- 0.45 and-1.80, respectively. As shown in Table 9, 12 lines were selected with positive index values and higher than the check varieties' index values. These lines showed the characteristics of days to harvesting (110.2-116.0 days), number of filled grains per panicle (70.6-101.3 grains), number of unfilled grains per panicle (27.9-58.4 grains), and productivity $\left(2.2-2.9\right.$ tons ha $\left.{ }^{-1}\right)$. The selected lines were further evaluated for their tolerance to drought stress and aluminum toxicity.

\section{Drought tolerance evaluation on the seedling stage}

The results of the drought tolerance evaluation are shown in Table 10. Leaf rolling is one of rice's acclimation responses against drought stress (Pandey and Shukla 2015). The scoring of the leaf rolling revealed that only one line, namely CG9-53-1-3, was categorized as tolerant (Table 10). This line had a leaf rolling response that was relatively similar to the drought-tolerant check Salumpikit. The scoring also showed that HR8-5-2-1 had a moderate leaf rolling response, while E38-CK1-BP and HR1-12-2-2 were categorized as mild sensitive (Table 10). The three lines had a better leaf rolling response than the IR20 variety as a drought-sensitive check. Meanwhile, eight lines had sensitive leaf rolling responses (Table 10). 
Table 7. Direct and indirect effects of several agronomic characters on productivity

\begin{tabular}{|c|c|c|c|c|c|c|c|c|}
\hline & \multirow{2}{*}{ Direct effect } & \multicolumn{6}{|c|}{ Indirect effect } & \multirow{2}{*}{$\begin{array}{c}\text { Correlation with } \\
\text { productivity }\end{array}$} \\
\hline & & DF & DH & NFG & NUG & PFG & PUG & \\
\hline $\mathrm{DF}$ & -0.05 & & -0.37 & -0.31 & -0.26 & 0.23 & 0.12 & $-0.63^{* *}$ \\
\hline $\mathrm{DH}$ & -0.42 & -0.04 & & -0.32 & -0.44 & 0.33 & 0.16 & $-0.72^{* *}$ \\
\hline NFG & 1.04 & 0.01 & 0.13 & & 0.15 & -0.56 & -0.23 & $0.54^{*}$ \\
\hline NUG & -1.50 & -0.01 & -0.12 & -0.10 & & 0.91 & 0.37 & $-0.46^{*}$ \\
\hline PFG & -1.03 & 0.01 & 0.13 & 0.56 & 1.32 & & -0.41 & $0.58^{* *}$ \\
\hline PUG & 0.42 & -0.01 & -0.16 & -0.57 & -1.31 & 1.01 & & $-0.62^{* *}$ \\
\hline
\end{tabular}

Note: Coefficient of determination $\left(\mathrm{R}^{2}\right)=72 \%$; Residual effect $=53 \%$; DF: days to flowering; DH: days to harvesting; NFG: number of filled grains; NUG: number of unfilled grains; PFG: percentage of filled grains; PUG: percentage of unfilled grains; **: highly significant at $1 \%$ level of significance; *: significant at $5 \%$ level of significance.

Table 8. Six principal components obtained from 13 agronomic traits

\begin{tabular}{lcccccc}
\hline \multicolumn{1}{c}{ Traits } & PC1 & PC2 & PC3 & PC4 & PC5 & PC6 \\
\hline Plant height & -0.07 & -0.29 & 0.06 & 0.48 & 0.40 & -0.48 \\
Number of productive tillers & -0.01 & 0.30 & -0.12 & -0.25 & 0.67 & 0.49 \\
Days to flowering & -0.23 & 0.04 & 0.52 & -0.25 & 0.16 & -0.03 \\
Days to harvesting & -0.14 & -0.02 & 0.59 & -0.18 & 0.01 & -0.11 \\
Panicle length & -0.14 & -0.38 & 0.14 & 0.25 & 0.40 & 0.23 \\
Panicle density & -0.08 & -0.43 & -0.18 & -0.40 & -0.23 & 0.06 \\
Number of filled grains & 0.31 & -0.40 & 0.10 & -0.21 & 0.06 & 0.07 \\
Number of unfilled grains & -0.46 & -0.16 & -0.18 & 0.00 & -0.04 & 0.11 \\
Number of total grains & -0.13 & -0.52 & -0.07 & -0.19 & 0.02 & 0.17 \\
Percentage of filled grains & 0.48 & -0.07 & 0.18 & -0.10 & 0.05 & -0.04 \\
Percentage of unfilled grains & -0.48 & 0.07 & -0.18 & 0.10 & -0.05 & 0.04 \\
Weight of 1000 grains & 0.00 & -0.03 & 0.39 & 0.46 & -0.37 & 0.61 \\
Productivity & 0.33 & -0.15 & -0.23 & 0.27 & 0.09 & 0.20 \\
Standard Deviation & 1.98 & 1.79 & 1.47 & 1.11 & 0.94 & 0.82 \\
Proportion of Variance & 0.30 & 0.25 & 0.17 & 0.09 & 0.07 & 0.05 \\
Cumulative Proportion & 0.30 & 0.55 & 0.71 & 0.81 & 0.87 & 0.93 \\
Eigen Values & 3.93 & 3.19 & 2.15 & 1.22 & 0.88 & 0.67 \\
\hline
\end{tabular}

Note: PC: principal component

Leaf rolling is a mechanism of drought avoidance against drought stress (Panda et al. 2021). The tolerant lines tend to had a lower leaf rolling rate and maintained the leaves' greenish condition. This response may be caused by deeper roots that allow sustained water uptake, the osmotic adjustment that preserves cell turgor, less leaf area, and slower water use (Garg et al. 2017). The response of leaf rolling can be slowed down if the cell turgor is wellmaintained. Nevertheless, increased leaf rolling under severe drought has the advantage of reducing water loss and radiation damage (Pandey and Shukla 2015).

Leaf drying is a subsequent response against drought stress that occurs after leaf rolling. The scoring results in Table 10 showed that the drought-tolerance check Salumpikit had the best response to leaf drying. In this study, there were no lines that were categorized as tolerant to leaf drying. As shown in Table 10, E33-CK1-BP and E38-CK1-BP were categorized as mild tolerant to leaf drying. Furthermore, HR1-12-2-2, HR8-5-2-1, and CG953-1-3 were categorized as moderate, while E4-CK1-BP and E8-CK1-BP were categorized as mild sensitive to leaf drying (Table 10). The seven lines had a better leaf drying response than the IR20 variety as a drought-sensitive check.
Drought stress reduces crop growth, which results in lower yields. The extent of the damage is determined by the intensity of the stress, its duration, and the plant's growth stage (Panda et al. 2021). Garg et al. (2017) reported that the response of leaf drying was negatively correlated with yields under drought conditions. Plants will adjust photosynthates partitioning among the organs under drought conditions. Drought stress increases the root-shoot ratio, indicating that photosynthates are partitioned more toward root formation and reduces canopy growth (Purwanto et al. 2017).

Drought recovery refers to the plants' capability to resume growth after experiencing the adverse effects of drought stress (Purwanto et al. 2017). The plant recovery ability evaluation showed that lines E33-CK1-BP, E38CK1-BP, CG9-53-1-3, and Salumpikit as a drought-tolerant check variety were categorized as tolerant (Table 10). Table 10 also shows that E4-CK1-BP and HR1-12-2-2 were categorized as moderate, while E8-CK1-BP was categorized as mild sensitive. These lines had better recovery ability than the IR20 variety as the droughtsensitive check. 
Table 9. Mean of the selection characters and weighted selection index of twenty upland rice lines and two check varieties

\begin{tabular}{|c|c|c|c|c|c|c|c|c|c|}
\hline \multirow[b]{2}{*}{ Genotype } & \multicolumn{4}{|c|}{ Mean of } & \multicolumn{4}{|c|}{ Z-value of } & \multirow[b]{2}{*}{$\begin{array}{c}\text { Weighted } \\
\text { index }\end{array}$} \\
\hline & $\begin{array}{c}\text { DH } \\
\text { (DAP) }\end{array}$ & NFG & NUG & $\begin{array}{c}\text { PRD } \\
(\text { ton ha-1) }\end{array}$ & DH & NFG & NUG & PRD & \\
\hline E-43-CK1-BP\# & 111.0 & 92.0 & 45.1 & 2.8 & 1.13 & 1.26 & -0.44 & -1.23 & 1.89 \\
\hline E-8-CK1-BP & 113.5 & 85.4 & 41.4 & 2.9 & 1.26 & 0.68 & -0.72 & -0.32 & 1.83 \\
\hline E-33-CK1-BP\# & 114.2 & 83.5 & 27.9 & 2.4 & 0.48 & 0.50 & -1.74 & -0.08 & 1.45 \\
\hline HR-1-12-2-2 & 115.0 & 101.3 & 31.6 & 2.2 & 0.13 & 2.08 & -1.47 & 0.22 & 1.42 \\
\hline E-37-CK1-BP\# & 114.5 & 86.6 & 43.8 & 2.6 & 0.78 & 0.77 & -0.55 & 0.04 & 1.26 \\
\hline E-4-CK1-BP & 115.3 & 91.8 & 41.6 & 2.5 & 0.55 & 1.24 & -0.71 & 0.34 & 1.21 \\
\hline CG-9-53-1-3 & 113.0 & 79.6 & 35.4 & 2.3 & 0.32 & 0.16 & -1.18 & -0.51 & 0.98 \\
\hline HR-8-5-2-1 $1^{\#}$ & 112.0 & 70.6 & 37.0 & 2.5 & 0.52 & -0.64 & -1.05 & -0.87 & 0.92 \\
\hline HR-5-7-1-1" & 110.2 & 72.9 & 51.8 & 2.5 & 0.52 & -0.44 & 0.06 & -1.53 & 0.57 \\
\hline HR-5-9-1-1" & 110.2 & 74.1 & 55.4 & 2.5 & 0.58 & -0.33 & 0.33 & -1.53 & 0.53 \\
\hline E-48-CK1-BP\# & 114.2 & 97.0 & 58.4 & 2.3 & 0.22 & 1.70 & 0.55 & -0.08 & 0.50 \\
\hline E-38-CK1-BP & 116.0 & 72.5 & 36.3 & 2.2 & -0.02 & -0.48 & -1.11 & 0.58 & 0.26 \\
\hline E-16-CK1-BP & 112.5 & 68.6 & 49.9 & 2.1 & -0.07 & -0.82 & -0.08 & -0.69 & -0.19 \\
\hline IR64 & 115.0 & 57.9 & 25.8 & 1.7 & -0.76 & -1.77 & -1.90 & 0.22 & -0.45 \\
\hline HR-6-5-1-3 & 116.5 & 66.8 & 50.0 & 2.1 & -0.20 & -0.98 & -0.08 & 0.76 & -0.57 \\
\hline CG-12-30-1-3 & 115.8 & 95.6 & 76.3 & 2.1 & -0.20 & 1.57 & 1.91 & 0.52 & -0.67 \\
\hline E-2-CK1-BP & 114.0 & 96.0 & 74.6 & 1.8 & -0.73 & 1.61 & 1.78 & -0.14 & -1.02 \\
\hline CG-9-5-1-2 & 113.5 & 65.8 & 66.8 & 2.0 & -0.28 & -1.07 & 1.19 & -0.32 & -1.12 \\
\hline HR-4-12-1-1 & 113.7 & 56.3 & 57.7 & 1.8 & -0.74 & -1.91 & 0.51 & -0.26 & -1.52 \\
\hline Inpago 10 & 117.7 & 80.1 & 72.3 & 1.6 & -0.97 & 0.21 & 1.60 & 1.18 & -1.80 \\
\hline HR-2-6-1-1 & 118.5 & 65.8 & 64.1 & 1.6 & -1.00 & -1.07 & 0.99 & 1.48 & -1.99 \\
\hline E-34-CK1-BP & 120.7 & 50.0 & 78.7 & 1.2 & -1.79 & -2.47 & 2.08 & 2.26 & -3.81 \\
\hline
\end{tabular}

Note: \#: the selected lines; DH: days to harvesting; DAP: days after planting; NFG: number of filled grains; NUG: number of unfilled grains; PRD: productivity

Swapna and Shylaraj (2017) reported that the plant recovery ability was significantly and positively correlated with drought tolerance. This correlation indicates that genotypes with good recovery ability also have good tolerance responses to drought stress. The ability to recover is essential. When plants undergo drought stress, their growth is slowed. Genotypes with great recovery ability have a faster growth rate after drought stress ceases (Akbar et al. 2018).

\section{Selection index for drought tolerance screening}

In this study, the character of recovery ability was considered more important than the other drought tolerance characters. Recovery ability is closely associated with plants' adaptability to drought stress than the other characters (Chen et al. 2016). Good recovery ability is essential to maintain high grain yields and can be used as a selection trait in developing drought-tolerant rice cultivars. Based on these considerations, the character of recovery ability was assigned a weighting two times higher than the weighting of leaf rolling and leaf drying. In this study, the weighting of drought tolerance characters was changed to negative values. This adjustment was intended to sort and interpret the selection index value for drought tolerance screening in descending order and select lines with positive index values. The weighted selection index model (I) for drought tolerance screening in this study was formulated as follows: $\mathrm{I}=(-1 \times \mathrm{LR})+(-1 \times \mathrm{LD})+(-2 \times \mathrm{RA})$ where $\mathrm{LR}$ was leaf rolling, $\mathrm{LD}$ was leaf drying, and RA was recovery ability.
Based on the selection index model, the droughttolerant check Salumpikit (9.24) had the highest index, while the drought-sensitive check IR20 (-4.58) had the lowest index (Table 10). These findings indicated that Salumpikit has the highest level of drought tolerance. In contrast, IR20 is the most vulnerable to drought stress. Four lines with positive and relatively high index values were selected. The four selected lines were CG9-53-1-3 (4.63), E38-CK1-BP (2.22), E33-CK1-BP (1.91), and HR112-2-2 (0.54). These lines have a better drought tolerance than the other lines.

\section{Evaluation of aluminum tolerance on the seedling stage}

The results of aluminum tolerance evaluation at 0 and $40 \mathrm{ppm} \mathrm{Al}$ are shown in Table 11. The RRL (relative root length) value in this study ranged from $0.36-0.73$. Limboto, as the aluminum-tolerant check variety, had the highest RRL of 0.73 , followed by the E33-CK1-BP and E37-CK1BP lines, with RRL values of 0.67 and 0.63 , respectively (Table 11). Contrarily, the aluminum-sensitive check variety ITA131 (0.36) and the CG9-53-1-3 line (0.40) showed the lowest RRL (Table 11). The E33-CK1-BP and E37-CK1-BP lines were both categorized as tolerant, while CG9-53-1-3 was the only line categorized as sensitive to aluminum toxicity. Based on Table 11, nine lines with RRL values ranged from $0.47-0.59$ were categorized as moderate to aluminum toxicity. The obtained lines with putative tolerant and putative moderate responses to aluminum toxicity could be further evaluated by direct selection on acid dryland. 
Table 10. Response of 12 upland rice on drought tolerance evaluation and weighted selection index

\begin{tabular}{|c|c|c|c|c|c|c|c|}
\hline \multirow{2}{*}{ Genotype } & \multicolumn{2}{|c|}{ Leaf rolling } & \multicolumn{2}{|c|}{ Leaf drying } & \multicolumn{2}{|c|}{ Plant recovery ability } & \multirow{2}{*}{$\begin{array}{l}\text { Index } \\
\text { value }\end{array}$} \\
\hline & Score & Response & Score & Response & Score & Response & \\
\hline E4-CK1-BP & 9 & Sensitive & 7 & Mild sensitive & 5 & Moderate & -1.16 \\
\hline E8-CK1-BP & 9 & Sensitive & 7 & Mild sensitive & 7 & Mild sensitive & -0.34 \\
\hline E33-CK1-BP\# & 9 & Sensitive & 3 & Mild Tolerant & 1 & Tolerant & 1.91 \\
\hline E37-CK1-BP & 9 & Sensitive & 9 & Sensitive & 9 & Sensitive & -3.71 \\
\hline E38-CK1-BP\# & 7 & Mild sensitive & 3 & Mild Tolerant & 1 & Tolerant & 2.22 \\
\hline E43-CK1-BP & 9 & Sensitive & 9 & Sensitive & 9 & Sensitive & -1.16 \\
\hline E48-CK1-BP & 9 & Sensitive & 9 & Sensitive & 9 & Sensitive & -2.86 \\
\hline HR1-12-2-2\# & 7 & Mild sensitive & 5 & Moderate & 5 & Moderate & 0.54 \\
\hline HR5-7-1-1 & 9 & Sensitive & 9 & Sensitive & 9 & Sensitive & -3.37 \\
\hline HR5-9-1-1 & 9 & Sensitive & 9 & Sensitive & 9 & Sensitive & -1.10 \\
\hline HR8-5-2-1 & 5 & Moderate & 5 & Moderate & 9 & Sensitive & -0.25 \\
\hline CG9-53-1-3 $3^{\#}$ & 1 & Tolerant & 5 & Moderate & 1 & Tolerant & 4.63 \\
\hline Salumpikit & 1 & Tolerant & 1 & Tolerant & 1 & Tolerant & 9.24 \\
\hline IR20 & 9 & Sensitive & 9 & Sensitive & 9 & Sensitive & -4.58 \\
\hline
\end{tabular}

Note: \#: The selected lines based on weighted selection index

Table 11. Response of 12 upland rice lines under aluminum stress conditions on the seedling stage

\begin{tabular}{lcccl}
\hline \multirow{2}{*}{ Genotype } & \multicolumn{2}{c}{ Root length $(\mathbf{c m})$} & \multirow{2}{*}{ RRL } & \multirow{2}{*}{ Response } \\
\cline { 2 - 4 } & $\mathbf{0}$ ppm Al & $\mathbf{4 0} \mathbf{~ p p m ~ A l}$ & & \\
\hline E4-CK1-BP & 11.6 & 6.5 & 0.56 & Moderate \\
E8-CK1-BP & 10.8 & 5.8 & 0.54 & Moderate \\
E33-CK1-BP & 11.1 & 7.4 & 0.67 & Tolerant \\
E37-CK1-BP & 10.6 & 6.7 & 0.63 & Tolerant \\
E38-CK1-BP & 14.3 & 8.4 & 0.59 & Moderate \\
E43-CK1-BP & 11.7 & 5.5 & 0.47 & Moderate \\
E48-CK1-BP & 10.4 & 5.5 & 0.53 & Moderate \\
HR1-12-2-2 & 11.0 & 5.5 & 0.50 & Moderate \\
HR5-7-1-1 & 11.0 & 5.4 & 0.49 & Moderate \\
HR5-9-1-1 & 11.2 & 5.7 & 0.51 & Moderate \\
HR8-5-2-1 & 11.3 & 5.3 & 0.47 & Moderate \\
CG9-53-1-3 & 14.1 & 5.7 & 0.40 & Sensitive \\
Limboto & 9.0 & 6.6 & 0.73 & Tolerant \\
ITA131 & 12.4 & 4.5 & 0.36 & Sensitive \\
\hline N
\end{tabular}

Note: RRL: relative root length

The root condition in the $40 \mathrm{ppm} \mathrm{Al} \mathrm{treatment} \mathrm{reflected}$ the plant's response under aluminum stress. All of the lines tested had shorter root lengths in the $40 \mathrm{ppm} \mathrm{Al}$ treatment than in the control treatment ( 0 ppm Al) (Table 11). Similar results were reported by Hermanasari et al. (2021) and Lu et al. (2020). Inhibition of root elongation is a clear, direct symptom and can be immediately observed in plants under aluminum stress ( $\mathrm{Lu}$ et al. 2020). Changes in root morphology, such as swelling, thickening, and discoloration, are also symptoms of aluminum toxicity (Rahman and Upadhyaya 2020). Siecińska et al. (2019) found that $\mathrm{Al}^{3+}$ in the sensitive line's roots accumulated 5.5 times faster than in the tolerant line's roots. Compared to aluminum-sensitive rice varieties, the roots of aluminumtolerant rice varieties have fewer functional groups and absorb less $\mathrm{Al}^{3+}$ (Lu et al. 2020).

In summary, this study has shown that there was an adequate variability among genotypes in agronomic characters, drought tolerance, and aluminum tolerance in the doubled haploid lines and the mutant lines of upland rice evaluated. Based on the selection index, 12 lines were selected with good agronomic characteristics and relatively higher productivity than IR64 and Inpago 10 check varieties. These lines consisted of E-4-CK1-BP, E-8-CK1BP, E-33-CK1-BP, E-37-CK1-BP, E-38-CK1-BP, E-43CK1-BP, E-48-CK1-BP, HR-1-12-2-2, HR-5-7-1-1, HR-59-1-1, HR-8-5-2-1, and CG-9-53-1-3. Evaluation of drought tolerance showed four lines (E-33-CK1-BP, E-38CK1-BP, HR-1-12-2-2, and CG-9-53-1-3) with better drought tolerance than the drought-sensitive check IR20. Meanwhile, the aluminum tolerance evaluation obtained two tolerant lines (E33-CK1-BP and E37-CK1-BP) and nine lines with a moderate response to aluminum toxicity. The E33-CK1-BP line was tolerant to aluminum and drought stress and could be recommended as a candidate for a multi-tolerant line. The selected lines need to be further evaluated for their agronomic performance and stability in multilocation trials.

\section{ACKNOWLEDGEMENTS}

The authors acknowledge the support of Indonesian Center for Agricultural Biotechnology and Genetic Resources Research and Development (ICABIOGRAD), Bogor, Indonesia for funding in parts of this research. The staff technical assistance of University Farm and the Department of Agronomy and Horticulture, IPB, Bogor, Indonesia is also acknowledged.

\section{REFERENCES}

Abebe T, Alamerew S, Tulu L. 2017. Genetic variability, heritability and genetic advance for yield and its related traits in rainfed lowland rice (Oryza sativa L.) genotypes at Fogera and Pawe, Ethiopia. Adv Crop Sci Tech 5: 2. DOI: 10.4172/2329-8863.1000272

Akbar MR, Purwoko BS, Dewi IS, Suwarno WB, Sugiyanta. 2018. Agronomic and drought tolerance evaluation of doubled haploid rice breeding lines derived from anther culture. SABRAO J Breed Genet 50 (2): 115-128.

Akbar MR, Purwoko BS, Dewi IS, Suwarno WB, Sugiyanta. 2019. Selection of doubled haploid lines of rainfed lowland rice in 
preliminary yield trial. Biodiversitas 20 (10): 2796-2801. DOI: 10.13057/biodiv/d201003

Akbar MR, Purwoko BS, Dewi IS, Suwarno WB, Sugiyanta S, Anshori MF. 2021. Agronomic and yield selection of doubled haploid lines of rainfed lowland rice in advanced yield trials. Biodiversitas 22 (7): 3006-3012. DOI: 10.13057/biodiv/d220754

Alsabah R, Purwoko BS, Dewi IS, Wahyu Y. 2019. Selection index for selecting promising doubled haploid lines of black rice. SABRAO J Breed Genet 51 (4): 430-441.

Anshori MF, Purwoko BS, Dewi IS, Ardie SW, Suwarno WB. 2021. A new approach to select doubled haploid rice lines under salinity stress using indirect selection index. Rice Sci 28 (4): 368-378. DOI: 10.1016/j.rsci.2021.05.007

Chen D, Wang S, Cao B, Cao D, Leng G, Li H, Yin L, Shan L, Deng X. 2016. Genotypic variation in growth and physiological response to drought stress and re-watering reveals the critical role of recovery in drought adaptation in maize seedlings. Front Plant Sci 6: 1241. DOI: $10.3389 /$ fpls.2015.01241

Dwivedi SL, Britt AB, Tripathi L, Sharma S, Upadhyaya HD, Ortiz R 2015. Haploids: Constraints and opportunities in plant breeding. Biotechnol Adv 33 (6): 812-829. 10.1016/j.biotechadv.2015.07.001

Falconer DS, Mackay TFC. 1996. Introduction to Quantitative Genetics. Longman, Essex

Garg HS, Kumar R, Kumar B, Singh AK. 2017. Screening and identification of rice genotypes with drought tolerance under stress and non-stress condition. Int J Chem Stud 5 (6): 1031-1042.

Gomez KA, Gomez AA. 1984. Statistical Procedures for Agricultural Research. John Wiley \& Sons, New York.

Hermanasari R, Lestari AP, Yullianida, Hairmansis A, Santoso, Nasution A. 2021. Yield ability and grain quality of upland rice in Sukabumi and Lampung. IOP Conf Ser: Earth Environ Sci 715 (1): 1-13. DOI: $10.1088 / 1755-1315 / 715 / 1 / 012030$

IRRI [International Rice Research Institute]. 2013. Standard Evaluation System for Rice. International Rice Research Institute, Los Baños.

Jolliffe IT, Cadima J. 2016. Principal component analysis: A review and recent developments. Phil Trans R Soc A 374: 1-15. DOI: 10.1098/rsta.2015.0202

Ministry of Agriculture Republic of Indonesia. 2019. Agricultural Statistics 2019. Center for Agricultural Data and Information System, Jakarta.

Kumar R, Vashisht P, Gupta RK, Singh M, Kaushal S. 2011 Characterization of european carrot genotypes through principal components and regression analyses. Int J Veg Sci 17 (1): 3-12. DOI $10.1080 / 19315260.2010 .486021$

Lu H, Dong G, Hua H, Zhao W, Li J, Xu R. 2020. Method for initially selecting Al-tolerant rice varieties based on the charge characteristics of their roots. Ecotoxicol Environ Saf 187: 1-8. DOI 10.1016/j.ecoenv.2019.109813

Mishra R, Rao GJN. 2016. In-vitro androgenesis in rice: Advantages, constraints and future prospects. Rice Sci 23 (2): 57-68. DOI: 10.1016/j.rsci.2016.02.001
Oladosu Y, Rafii MY, Magaji U, Abdullah N, Miah G, Chukwu SC, Hussin G, Ramli A, Kareem I. 2018. Genotypic and phenotypic relationship among yield components in rice under tropical conditions. BioMed Res Int 2018: 8936767. DOI: $10.1155 / 2018 / 8936767$

Panda D, Mishra SS, Behera PK. 2021. Drought tolerance in rice: Focus on recent mechanisms and approaches. Rice Sci 28 (2): 119-132. DOI: 10.1016/j.rsci.2021.01.002

Pandey V, Shukla A. 2015. Acclimation and tolerance strategies of rice under drought stress. Rice Sci 22 (4): 147-161. DOI: 10.1016/j.rsci.2015.04.001

Pitoyo AJ, Ulhaq MD, Wahid A, Taqiyyah S. 2018. System dynamics modeling of Indonesia population projection model. IOP Conf Ser: Earth Environ Sci 145: 1-8. DOI: 10.1088/1755-1315/145/1/012117

Purwanto E, Samanhudi S, Effendi Y. 2017. Response of some upland rice varieties to drought stress. Trop Drylands 1 (2): 69-77. DOI: $10.13057 /$ tropdrylands/t010202

Rahman R, Upadhyaya H. 2020. Aluminium toxicity and its tolerance in plant: A review. J Plant Biol 64: 101-121. DOI: 10.1007/s12374-02009280-4

Saha SR, Hassan L, Haque MA, Islam MM, Rasel M. 2019. Genetic variability, heritability, correlation and path analyses of yield components in traditional rice (Oryza sativa L.) landraces. J Bangladesh Agric Univ 17 (1): 26-32. DOI: 10.3329/jbau.v17i1.40659

Saito K, Asai H, Zhao D, Laborte AG, Grenier C. 2018. Progress in varietal improvement for increasing upland rice productivity in the tropics. Plant Prod Sci 21 (3): 145-158. DOI: 10.1080/1343943X.2018.1459751

Sari SN, Purwoko BS. 2018. Yield trial of doubled haploid lines of lowland rice obtained from anther culture. Bul Agrohorti 6 (1): 68-77. DOI: 10.29244/agrob.v6i1.16825 [Indonesian]

Siecińska J, Wiącek D, Przysucha B, Nosalewicz A. 2019. Drought in acid soil increases aluminum toxicity especially of the Al-sensitive wheat. Environ Exp Bot 165: 185-195. DOI: 10.1016/j.envexpbot.2019.06.007

Singh RK, Chaudhary BD. 1979. Biometrical Methods in Quantitative Genetic Analysis. Kalyani Publishers, Ludhiana.

Sudeepthi K, Srinivas T, Kumar BNVSRR, Jyothula DPB, Umar SN. 2020. Assessment of genetic variability, character association and path analysis for yield and yield component traits in rice (Oryza sativa L.). Eur J Pharm Biopharm 11 (1): 144-148. DOI: $10.37992 / 2020.1101 .026$

Swapna S, Shylaraj KS. 2017. Screening for osmotic stress responses in rice varieties under drought condition. Rice Sci 24 (5): 253-263. DOI: 10.1016/j.rsci.2017.04.004

Tijarah SK. 2016. Advanced Yield Trial of Lowland Rice Lines (Oryza sativa L.) Tolerant to Drought Obtained from Anther Culture. [Thesis]. Bogor Agricultural University, Bogor. [Indonesian]

Viana VE, Pegoraro C, Busanello C, de Oliveira AC. 2019. Mutagenesis in rice: The basis for breeding a new super plant. Front Plant Sci 10: 1326. DOI: $10.3389 /$ fpls.2019.01326 